\title{
Climate-induced hysteresis of the tropical forest in a fire-enabled Earth system model
}

\author{
Markus Drüke ${ }^{1,2, a}$, Werner von Bloh ${ }^{1}$, Boris Sakschewski ${ }^{1}$, Nico Wunderling ${ }^{1,2,3}$, Stefan Petri ${ }^{1}$, \\ Manoel Cardoso ${ }^{4}$, Henrique M. J. Barbosa ${ }^{5}$, and Kirsten Thonicke ${ }^{1}$ \\ 1 Potsdam-Institute for Climate Impact Research, Member of the Leibniz Association, P.O. Box 601203 , 14412 Potsdam, \\ Germany \\ 2 Humboldt Universität zu Berlin, Unter den Linden 6, 10099 Berlin, Germany \\ 3 Institute of Physics and Astronomy, University of Potsdam, 14476 Potsdam, Germany \\ ${ }^{4}$ Instituto Nacional de Pesquisas Espaciais, Av. dos Astronautas, 1.758 - Jardim da Granja, São José dos Campos, \\ SP 12227-010, Brazil \\ ${ }^{5}$ Physics Institute, University of Sao Paulo (USP), R. do Matão, 1371, Cidade Universitária, SP, Brazil
}

Received 30 October 2020 / Accepted 21 April 2021 / Published online 14 June 2021

(C) The Author(s) 2021

\begin{abstract}
Tropical rainforests are recognized as one of the terrestrial tipping elements which could have profound impacts on the global climate, once their vegetation has transitioned into savanna or grassland states. While several studies investigated the savannization of, e.g., the Amazon rainforest, few studies considered the influence of fire. Fire is expected to potentially shift the savanna-forest boundary and hence impact the dynamical equilibrium between these two possible vegetation states under changing climate. To investigate the climate-induced hysteresis in pan-tropical forests and the impact of fire under future climate conditions, we employed the Earth system model CM2Mc, which is biophysically coupled to the fire-enabled state-of-the-art dynamic global vegetation model LPJmL. We conducted several simulation experiments where atmospheric $\mathrm{CO}_{2}$ concentrations increased (impact phase) and decreased from the new state (recovery phase), each with and without enabling wildfires. We find a hysteresis of the biomass and vegetation cover in tropical forest systems, with a strong regional heterogeneity. After biomass loss along increasing atmospheric $\mathrm{CO}_{2}$ concentrations and accompanied mean surface temperature increase of about $4{ }^{\circ} \mathrm{C}$ (impact phase), the system does not recover completely into its original state on its return path, even though atmospheric $\mathrm{CO}_{2}$ concentrations return to their original state. While not detecting large-scale tipping points, our results show a climate-induced hysteresis in tropical forest and lagged responses in forest recovery after the climate has returned to its original state. Wildfires slightly widen the climate-induced hysteresis in tropical forests and lead to a lagged response in forest recovery by ca. 30 years.
\end{abstract}

\section{Introduction}

Tropical forests play a key role in the Earth's climate system and provide important ecosystem services [1]. Being one of the most productive biomes and largest terrestrial carbon stores, they stabilize global climate and thus the Earth system. By recycling 25-50\% of total rainfall, Amazon rainforests are a huge atmospheric moisture pump, thereby regulating regional climate by evaporative cooling and conserving soil and water in South America [2]. Furthermore, tropical forests provide timber, fiber, fuel wood and non-timber forest products thus ensuring not only local livelihoods [3]. Tropical forests are also the largest global reserve of biodiversity $[4,5]$. Today this crucial functionality is at risk as land use change (LUC) and climate change (CC) pose an ever growing threat to tropical forests. Logging, slash and burn practices, drought and temper-

\footnotetext{
a e-mail: drueke@pik-potsdam.de (corresponding author)
}

ature stress, as well as increasing fire regimes threaten the survival of large areas of tropical forests [6-10].

In particular, the interaction between fire, vegetation and climate plays a key role for the geographic distribution of tropical forests and might lead to a vast transition from forest to non-forest states, such as savannas and grasslands $[11,12]$. In a dense forest, the closed canopy favors a moist and relatively cool micro-climate, which prevents fire and stabilizes the forest state [13]. However, increasing fire regimes, through LUC and CC, degrade forests and decrease canopy closure specifically at the forest perimeter [14]. As a consequence, fuel at the forest floor dries out more and grass cover increases, which in turn increases fire frequency due to easily ignitable fine fuels. In addition, a grassy environment leads to a dry, hot and windy micro-climate, further increasing fire regimes. Frequent fires are thought to prevent the establishment of new trees and stabilizing the grassland state $[13,14]$. Fire and deforestation can change vegetation-climate feedbacks in tropical forests 
in such a way that multiple stable states are possible implying a hysteresis in the impact and recovery phase of the system $[15,16]$. For example, a disturbance by elevated atmospheric $\mathrm{CO}_{2}$ levels and hence, higher temperatures, could increase tree mortality, enhance grass growth and push the system towards a less vegetated state. With fires burning more frequently in grassland and savanna ecosystems, tree recovery could be prevented under decreasing temperatures and atmospheric $\mathrm{CO}_{2}$ concentrations, thus leading to a lock-in effect and bistable states [13]. Similar mechanisms were found for atmospheric moisture recycling [17] and deforestation [18].

Such system hysteresis is often accompanied by the existence of tipping points, where relatively small disturbances can cause a transition from one system state to another. Several previous studies indicate the presence of such tipping points and stable states in tropical forests $[13,16,18-22]$. Bistability between grassland and trees has been investigated by, e.g., Baudena et al. [20], using a simple conceptual model. They found a possible coexistence between grassland and trees. While fire widens the parameter range for the coexistence it also induces a bistability between forest and grasslands. Especially in the transition zones between grasslands and forests fire-sensitive tipping points exists. This has be shown by Lasslop et al. [13], using a fireenabled dynamic global vegetation model (DGVM). Another study identified three stable states (forest, savanna and grassland) by analyzing remote sensing data (Hirota et al. [16]). They also found that deforestation to the threshold of $60 \%$ tree cover might lead to a self-propagating shift to an open savanna state. Recently, several tipping points of tropical forests for different regions and climatic conditions were found by Staal et al. [21]. Using integrated remote sensing data, a hydrological model and atmosphere moisture tracking simulations, they emphasized the importance of moisture recycling in forests for the spatial extent of tropical forests.

Most of these studies rely on conceptual models, uncoupled simulations or remote sensing data - hardly ever on Earth system models. However, neither conceptual models nor stand-alone DGVMs (not coupled to an Earth system model) can account for multiple feedbacks between vegetation and climate, and using historical data does not allow to investigate various scenarios and processes separately. Nevertheless, investigating the tropical hysteresis using a fire-enabled and stateof-the-art DGVM coupled to an Earth system model (ESM) still remains a challenge, because of the complexity of such a models and computational demands.

In this study, we aimed to investigate the potential for a climate-induced hysteresis and multiple stable states using the fire-enabled DGVM LPJmL, coupled to the ESM CM2Mc. Starting from a pre-industrial potential natural vegetation state (vegetation that establishes under climate and soil conditions in a particular area or grid cell in the absence of human influence such as land use), we investigated the response of tropical forests to a linear increase of atmospheric $\mathrm{CO}_{2}$ over a 350-year time span. To study the recovery of the tropical forests, i.e., potential hysteresis and bistability, we decreased atmospheric $\mathrm{CO}_{2}$ afterwards by the same amount and over the same time span. The aim of these idealized climate change scenarios was not to represent a realistic historic or future atmospheric greenhouse gas concentration but to investigate the response of the model to an extreme warming scenario. In addition, to disentangle the impact of fire on tree mortality and recovery, we performed simulation experiments with and without fire. The impact of changing climate, forced by atmospheric $\mathrm{CO}_{2}$, and thus fire on vegetation was quantified by changes in the time series of average tropical biomass and by evaluating spatial differences between the different experiments.

\section{Methods}

\section{$2.1 \mathrm{CM} 2 \mathrm{Mc}-\mathrm{LPJ} \mathrm{mL}$}

We used the coupled Earth system model CM2McLPJmL v.1.0 (see Fig. 1), which combines the fast but coarse-grained atmosphere and ocean model CM2Mc [23] with the state-of-the-art DGVM LPJmL5.0-FMS $[24,25]$, using the process-based fire model SPITFIRE [26] which was recently optimized for South America [27]. The technical details of the biophysical coupling between CM2Mc and LPJmL are published in a separate article $[28] .^{1}$

\subsubsection{CM2Mc}

CM2Mc is a configuration of the Climate Model 2 (CM2) [29] model framework of the Geophysical Fluid Dynamics Laboratory (GFDL), which is coupled to the Modular Ocean Model 5 (MOM5) at a coarse spatial resolution of $3^{\circ} \times 3.75^{\circ}$ latitude-longitude [23]. The original configuration of the model includes the global atmosphere and land model AM2-LM2 [30] with static vegetation. In the configuration of CM2Mc-LPJmL, the land model LM2 is replaced by the dynamic global vegetation model LPJmL, while keeping MOM5 dynamically coupled. The model components are connected via GFDL's Flexible Modeling System (FMS), which is a software framework to support the efficient software development, coupling and application of its land, atmosphere and ocean components [31].

\subsubsection{LPJmL}

The Lund-Potsdam-Jena managed Land version model (LPJmL5.0-FMS, based on LPJmL4.0 $[24,32]$ and LPJmL5.0 [25]) is a well-established and validated process-based DGVM, which globally simulates the surface energy balance, water fluxes, carbon fluxes and stocks for natural and managed vegetation forced by climate and soil input data. LPJmL simulates the

\footnotetext{
1 Submitted to Geoscientific Model Development.
} 
establishment, growth, competition and mortality of plant functional types (PFT) in natural vegetation and crop functional types (CFT) on managed land. Vegetation composition results from changes in foliar projective cover (FPC) of competing PFTs. The establishment and survival of different PFTs is regulated through bioclimatic limits and effects of heat, productivity and fire on plant mortality. These processes enable LPJmL to investigate feedbacks, for example, between vegetation and fire. LPJmL simulates water balance [33], impacts of agriculture [34], wildfires in natural vegetation (SPITFIRE) [26], permafrost [35] and specified multiple climate drivers on phenology [36]. Recently, using an optimization approach, several important parameters in LPJmL have been newly estimated [37] and the fire model has been improved by developing a new fire danger index, to obtain a more realistic fire representation [27]. We applied the optimized and improved SPITFIRE in this study.

\subsubsection{Coupling interface}

The biophysical coupling of LPJmL in CM2Mc consists of canopy humidity, soil and canopy temperature, roughness length and albedo, that interact with the atmosphere in a temporal resolution of $1 \mathrm{~h}$. These variables are calculated within LPJmL and then passed to the coupling software FMS. The coupler provides LPJmL with the necessary climatic input as, i.e., radiation and precipitation (Fig. 1). The spatial resolution of the atmosphere and ocean is $3^{\circ} \times 3.75^{\circ}$ latitudelongitude, while LPJmL uses its native resolution of a $0.5^{\circ} \times 0.5^{\circ}$ latitude-longitude grid. The FMS interpolates the variables exchanged in both directions, guaranteeing conservation of all scalar and vector fields. Thus, the atmospheric input in one grid cell is distributed over several biosphere grid cells.

To couple LPJmL with CM2Mc, several adjustments in LPJmL had to be implemented, including the use of the Penman Monteith scheme [38] for the calculation of potential evapotranspiration and the modeling of canopy humidity. We furthermore included the calculation of surface temperature by employing a simple energy balance parameterization. Roughness lengths and albedo have been calculated as in stand- alone LPJmL [24]. To counteract a large negative temperature bias in the northern latitudes, we added a more detailed parameterization of the sublimation [39]. To make the LPJmL grid compatible with the FMS grid, a small wrapper library for the data exchange between LPJmL and the FMS domain was developed.

The detailed description of the coupling between CM2Mc and LPJmL and a thorough evaluation is published in a separate article [28].

\subsection{Experimental setup}

To ensure our simulation experiments start from an equilibrium of long-term soil and ocean carbon pools, we used a 5000-year stand-alone LPJmL spin up and restart files from CM2Mc. This first model spin-up was followed by a second spin-up by running the fully coupled model for 750 simulation years under pre-industrial conditions without land use, but with fire disturbance enabled. This second spin-up ensured a consistent equilibrium between soil, vegetation and climate.

To investigate the existence of a climate-induced hysteresis in tropical forests, we conducted a set of simulation experiments based on the following protocol which included three phases:

1. Impact phase: Linear increase of atmospheric $\mathrm{CO}_{2}$ level by $1 \%$ (from $284 \mathrm{ppm}$ ) per year, starting from pre-industrial conditions at $284 \mathrm{ppm}$ over 350 years, reaching a final $\mathrm{CO}_{2}$ level of $1280 \mathrm{ppm}$.

2. Recovery phase: Subsequent linear $\mathrm{CO}_{2}$ decrease, according to the impact phase, reaching $284 \mathrm{ppm}$ after 350 simulation years.

3. Post-recovery phase: 350 additional years with constant $\mathrm{CO}_{2}$ at $284 \mathrm{ppm}$ to establish the experiment closer to an equilibrium state.

To investigate the contribution of fire, we repeated the spin-up and the three phases in another set of simulation experiments but with fire disabled (no-fire). The $1 \% \mathrm{CO}_{2}$ concentration increase is an accepted method to force idealized climate change scenarios [40]. To focus on the main drivers of the climate-induced hysteresis in an already complex ecosystem, we turned land use off to have an undisturbed potential natural vegetation (since SPITFIRE does not work on managed land, the inclusion of land use would skew the results), and disabled $\mathrm{CO}_{2}$-fertilization and the nitrogen cycle within LPJmL. Aerosols, greenhouse gases besides $\mathrm{CO}_{2}$, ozone and solar irradiance were set to pre-industrial values from 1860, which allowed to isolate the impact of increasing $\mathrm{CO}_{2}$ and fire on natural vegetation. The experiments were performed globally, but we analyzed simulation results covering the tropical latitudes $30^{\circ} \mathrm{S}$ to $30^{\circ} \mathrm{N}$ only.

\section{Results and discussion}

\subsection{Trajectories of tropical biomass and temperature}

In the impact phase of the experiments, where atmospheric $\mathrm{CO}_{2}$ increased from 284 to $1280 \mathrm{ppm}$ over a period of 350 years, average tropical surface temperature (called temperature, hereafter) increased by ca. $4.1{ }^{\circ} \mathrm{C}$ with and without fire (Fig. 2a). Alongside the temperature increase in the impact phase, the modeled biomass decreased by ca. $20 \%$ for both experiments (Fig. 2b). Previous studies suggest temperature stress on the vegetation as the cause for this large reduction [41]. Without fire, the total biomass was ca $25 \%$ larger, due to missing combustion and fire-related tree mortality [42]. 
Fig. 1 Schematic overview of the coupling and the model components in CM2Mc-LPJmL

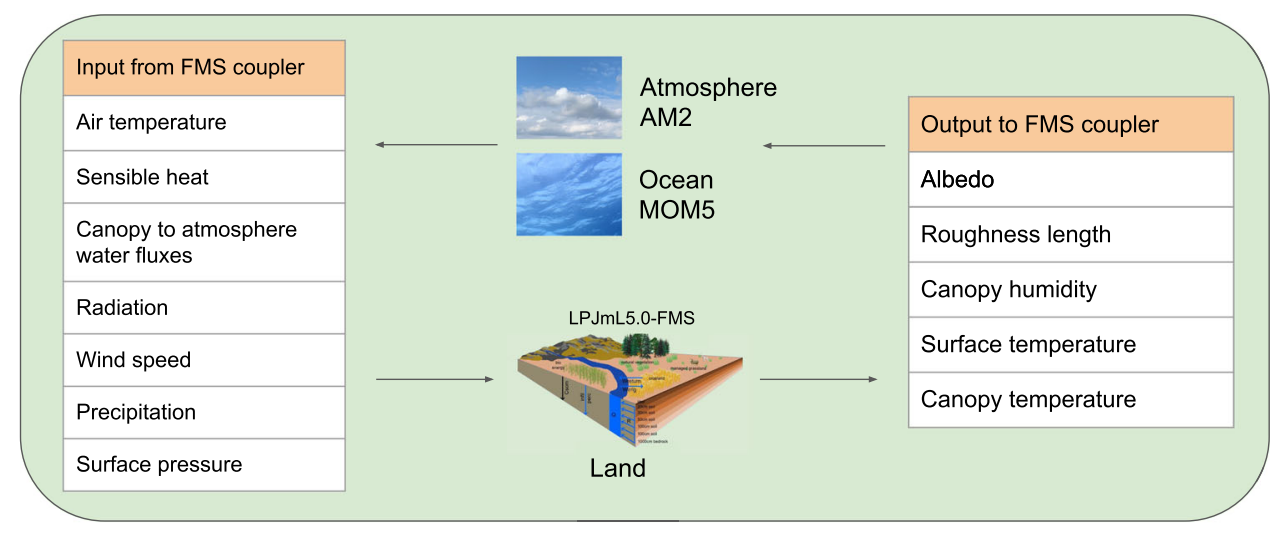

In the recovery phase, atmospheric $\mathrm{CO}_{2}$ decreased over another 350 years, until the starting value of 284 ppm was reached. In the first years of climate recovery, the temperature decrease was rather small, due to a delay in the response of the surface to the new $\mathrm{CO}_{2}$ values. After ca. 100 years, the temperature decreased faster and finally reached a value of ca. $0.7^{\circ} \mathrm{C}$ above the starting value of the impact phase for both experiments.

This temperature offset occurs for two reasons: (1) The temperature was not yet in a radiative equilibrium with the new $\mathrm{CO}_{2}$ values, which takes a few years, given no other interactions between temperature and vegetation [43]. (2) At the end of the recovery phase the vegetation was in a different state compared to the beginning. Average vegetation carbon (orange and light-blue lines in Fig. 2b) were still ca. $10 \%$ lower than at the beginning of the impact phase. Here, a lower biomass showed less evaporative cooling, leading to a higher temperature. Both effects, higher temperature and less biomass, are highly connected and strengthen this offset [44]. In the post-recovery phase of the experiments, atmospheric $\mathrm{CO}_{2}$ was kept constant at $284 \mathrm{ppm}$ for 350 years, to investigate lagged effects of the reverse trajectory in the climate-induced hysteresis in tropical forests. In both experiments, the temperature decreased rapidly over the first $10-20$ years, reaching the radiative equilibrium at the lower $\mathrm{CO}_{2}$ value of $284 \mathrm{ppm}$. In the remaining ca. 330 years, the temperature decreased much slower from ca. $0.3-0.4{ }^{\circ} \mathrm{C}$ to $0.1-0.2{ }^{\circ} \mathrm{C}$ above the starting value in the first experiment. Even at the end of the post-recovery phase, the temperature was still slightly elevated and did not reach its original state yet. Biomass continued to recover slowly (by ca. 10\%) in this last phase. To estimate the rate of recovery, we subtracted the standard deviation of the last 100 years (where biomass was relatively stable) from the mean of this period. The resulting value has been reached by the fire-enabled experiment (light grey line, Fig. 2b) after ca. 160 years of the post-recovery phase and by the no-fire experiment (black line, Fig. 2b) after ca. 130 years. Hence, the experiment without fire recovered slightly faster than the experiment with fire disturbance enabled. After 200 years of the post-recovery phase, the biomass was relatively stable for both experiments and approximately as large as in the initial state.

\subsection{Spatial heterogeneity}

The response of vegetation and climate in the conducted experiments had a strong regional variation. Here, we discuss the spatial heterogeneity of how tropical biomass, vegetation cover type and precipitation responded to the different $\mathrm{CO}_{2}$ trajectories (fire disturbance included) across the tropics.

In the fire-enabled experiment, temperature was still slightly elevated but average biomass had recovered after ca. 200 years of the post-recovery phase. This behavior can be explained by nonlinear effects in the vegetation-climate interaction in combination with regionally different biomass changes (Fig. 3). Figure $3 \mathrm{a}$ shows the distribution of biomass in the state before the impact phase. Here, highest values (25$35 \mathrm{kgC} / \mathrm{m}^{2}$ ) were found close to the equator. Savanna areas, as the Cerrado in Brazil or the Sahel zone, had biomass values of ca. $10-20 \mathrm{kgC} / \mathrm{m}^{2}$. Panels bd of Fig. 3 show the absolute difference in biomass comparing the three phases, thus areas with a large biomass exhibited the largest magnitude of change. These most affected areas lost almost half of their respective biomass $\left(10-15 \mathrm{kgC} / \mathrm{m}^{2}\right)$ throughout the impact phase (e.g., Amazon and African rainforests), but still maintained biomass levels higher than is usually found in tropical grassland areas of ca. $2-3 \mathrm{kgC} / \mathrm{m}^{2}$. Only a few, cooler regions offered better growing conditions in a $4{ }^{\circ} \mathrm{C}$ warmer climate, mostly mountain ranges, such as the Andes. These biomass increases are supported by earlier studies showing that higher temperatures could lead to a greening of mountainous regions [45]. At the end of the recovery phase, much of the biomass recovered (Fig. 3c), except northern Amazon and northern Central-African forests where biomass was still ca. $3-5 \mathrm{~kg} / \mathrm{m}^{2}$ lower. Biomass loss affected also African savannas (Fig. 3b, c). Regions that gained biomass from elevated temperatures, continued this trend (Fig. 3c).

After atmospheric $\mathrm{CO}_{2}$ levels returned to the preimpact state, biomass recovery still required 200 years of the post-recovery phase to reach its original state in most regions (Fig. 3d). Even after these additional 200 years, vulnerable regions, such as the northern Amazon and savannas in northern Africa, still did not 

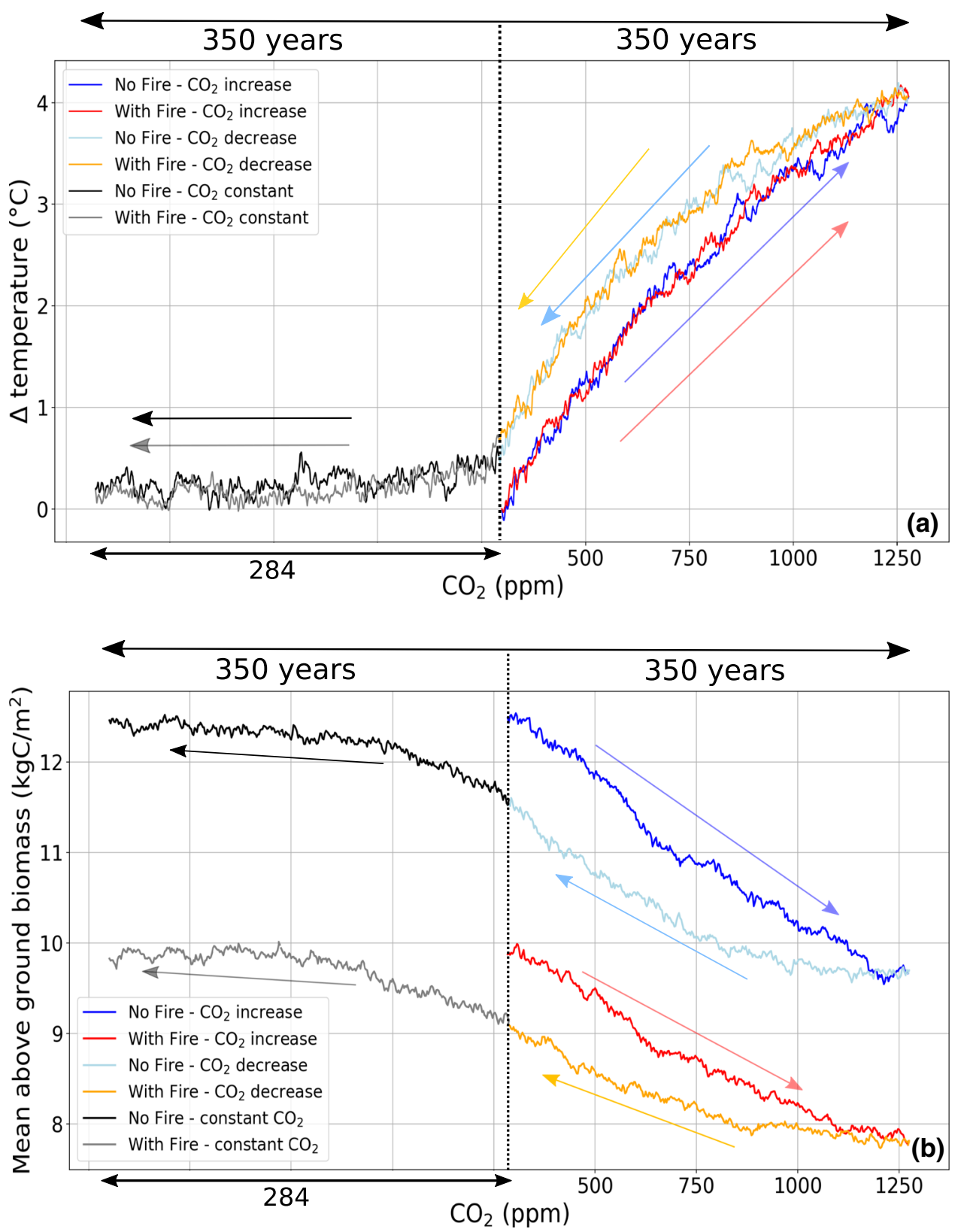

Fig. 2 a Overview of tropical mean land surface temperature for the simulation experiments. Atmospheric $\mathrm{CO}_{2}$ is increasing from $284 \mathrm{ppm}$ to $1280 \mathrm{ppm}$ in 350 years, leading to warming of $4.1^{\circ} \mathrm{C}$ in the no-fire (blue line) as well as fireenabled (red line) experiments, respectively. In the recovery phase experiments, $\mathrm{CO}_{2}$, and hence tropical surface temperature, decreases again for another 350 simulation years (fireenabled - orange line; no-fire-light blue line). Each experiment is then continued for another 350 simulation years under pre-industrial conditions marking the post-recovery phase (fire-enabled - light grey line; no-fire - dark grey line).

fully recover. Conversely, regions such as the Caatinga in northeastern Brazil, showed an even larger biomass compared to the beginning of the impact phase. This is due to a slightly wetter climate, caused by temperature changes, impacting the Atlantic ocean and hence, b Overview of tropical mean above-ground biomass for the simulation experiments. Atmospheric $\mathrm{CO}_{2}$ is increasing from 284 to $1280 \mathrm{ppm}$ in 350 years, leading to a decrease in biomass of ca. $20 \%$ in the no-fire (blue line) and fireenabled (red line) experiments, respectively. In the reverse experiments, $\mathrm{CO}_{2}$ decreases again for another 350 simulation years, followed by an increase in biomass (fire-enabledorange line; no-fire-light blue line). Each experiment is then continued for another 350 simulation years under preindustrial conditions (fire-enabled - light grey line; no-firedark grey line)

the precipitation in northeastern Brazil (Fig. 3f). Similarly, biomass increased along increasing precipitation in eastern Africa. On the contrary, biomass decreased in India and China, which is connected to a decrease in precipitation (Fig. 3f). Comparing Figs. $2 \mathrm{~b}$ and 3 

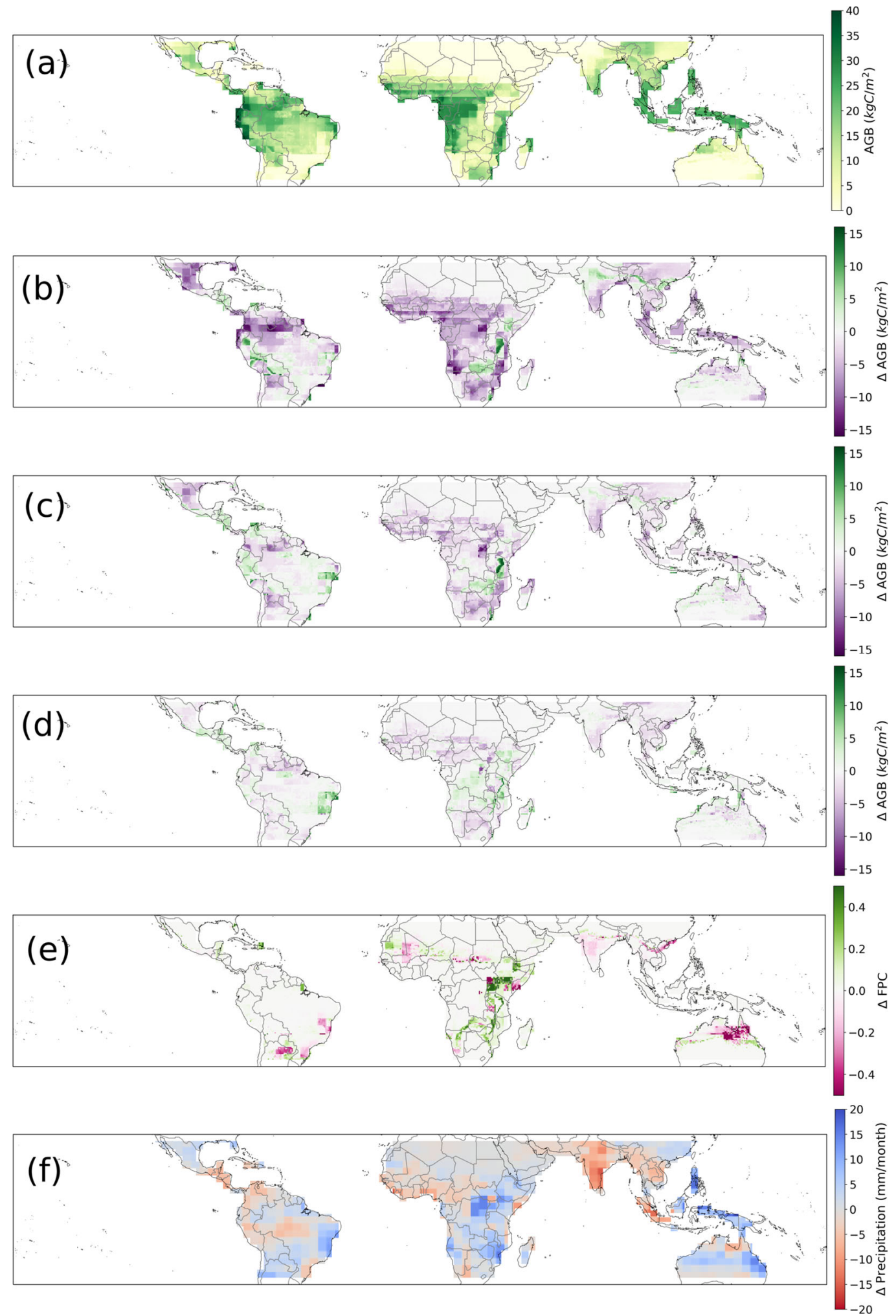

Fig. 3 a Simulated above-ground biomass (AGB) at the beginning of the experiments at $284 \mathrm{ppm}$ with fire activated. b Difference between (a) and the end of the impact phase after the first 350 years reaching $1280 \mathrm{ppm}$. c Difference between (a) and the end of the recovery phase after another 350 years reaching $284 \mathrm{ppm}$ again. $\mathbf{d}$ Difference between (a) and after 200 years of the post-recovery phase, after simu- lating another 200 years under constant $\mathrm{CO}_{2}$ of $284 \mathrm{ppm}$. e Difference of foliar projective cover (FPC) of tropical trees between the beginning of impact phase and the state after 200 years of the post-recovery phase. $\mathbf{f}$ Difference of global precipitation between the beginning of impact phase and the state after 200 years of the post-recovery phase 
shows, that even with almost completely restored average biomass after 200 years of the post-recovery phase, regional differences still remained and the original state was not completely restored.

While biomass was changed throughout the different phases of the experiment, also the vegetation composition reacted to the impact of changing $\mathrm{CO}_{2}$ concentrations (Fig. 3e). For some small regions in, e.g., the Brazilian Cerrado and northern Australia, the fraction of tropical trees decreased by ca. 0.1 and 0.3 between the start of the impact phase and the state after 200 years of the post-recovery phase. Hence, the vegetation cover switched to a more grassy environment. In some mountainous areas in eastern Africa, the fraction increased by $0.2-0.3$, indicating a shift towards forest. These changes correspond quite well to the differences in biomass (Fig. 3d) and precipitation (Fig. 3f).

\subsection{The hysteresis of the tropical forest}

We clearly observed in our study a hysteresis in time between the impact and recovery phases of the tropical forests. After completing the recovery phase, tropical average biomass was still decreased by ca. $10 \%$ compared to the original value and needed 200 more years at constant $\mathrm{CO}_{2}$ to reach the value it had at the beginning of the impact phase.

Various regions showed a different response to our experiment ranging from an overall increase of biomass to an incomplete recovery (decrease) after 200 years of the post-recovery phase. A transition to another stable state of vegetation cover was, however, only detected in small regions, which were sparsely vegetated at the beginning. This was the case for a transition to a more grassy and less woody environment in, e.g., the Cerrado or northern Australia and for a transition to a more woody environment in, e.g., eastern Africa. These shifts went along with changes in the precipitation patterns, as well as increased average tropical surface temperature after 200 years of the post-recovery phase.

While part of the observed hysteresis was due to the normal recovery time of the vegetation after a disturbance, a large part can be ascribed to dynamic changes in the vegetation-climate interactions: Some regions, as, e.g., the northern Amazon, showed a very tight vegetation-climate interaction by a strong response to higher temperatures and a slow recovery. Mountainous regions were able to establish more trees in warmer climate, which led to more precipitation and stabilized the new vegetation cover. Our results show, that an impact through elevated atmospheric $\mathrm{CO}_{2}$ concentrations disturbs climate-vegetation interactions and their co-evolution over centuries.

We find, however, that biophysical interactions between climate and vegetation, including fire, cannot push complete biomes, such as the entire Amazon rainforest, to a point beyond recovery. Other perturbations such as deforestation or factors such as biogeochemical coupling, incl. respective fire effects, might increase the probability of such tipping events. For example,
Lasslop et al. [13], Hirota et al. [16], Baudena et al. [20] and Staal et al. [21] found tipping points and bistability in the tropical forests using different methods. While we used a biophysically fully coupled, fireenabled Earth system model for this study and investigated the climate-induced hysteresis, these studies focused on land use change scenarios alongside climate change using simpler model approaches, remote sensing data or conceptional models. CM2Mc-LPJmL employs a state-of-the-art DGVM, which is fully biophysically coupled to an atmosphere. Hence, we have included several positive and negative feedback processes, including (1) the impact of evaporation on the temperature and precipitation, (2) the impact of roughness lengths, albedo and wind on the temperature, (3) the impact of shifting PFTs on the water cycle [46] and (4) fire dynamics [26]. Incorporating further important model features would improve our process understanding of the climate-induced hysteresis in tropical forests. For instance, accounting for the fertilizing effect of elevated atmospheric $\mathrm{CO}_{2}$ concentration on vegetation growth would most likely lead to overall higher biomass accumulation as anticipated in this study. We decided to neglect this effect in this study, since $\mathrm{CO}_{2}$-fertilization can be limited by other factors such as nutrient availability [47] or leaf cooling [48], which are not accounted for in this model version either. Including related processes such as the nitrogen cycle [25] and implementing the calculation of explicit leaf temperatures is in the scope of further studies. Furthermore, accounting for natural plant trait diversity, e.g., a continuum of tree rooting strategies, could reduce simulated drought stress and thus increase biomass resilience under changing climate [46]. The inclusion of a realistic land use pattern in the modeling experiments would lead to less fire and a lower mean biomass at the beginning of the experiments. Since the parameters chosen to simulate crop growth in LPJmL are similar to the respective physiological parameters for natural plant types, crop biomass would also decline with increasing heat stress.

In the experiments of this study, fire had a strong influence on biomass stocks, leading to about $25 \%$ lower biomass throughout all phases of the experiment (Fig. $2 \mathrm{~b})$. This effect of fire has also been shown by Lasslop et al. [42]. Nonetheless, the impact of fire on the decrease and increase biomass was small in the impact and recovery phase. Only towards the end of the recovery phase and the first half of the post-recovery phase, fire slightly delayed the increase of biomass, hence the system needed more time to reach a near-equilibrium (Fig. 2b). The temperature recovery was however very similar for both experiments (Fig. 2a). The described hysteresis of vegetation cover was observed in both experiments with and without fire disturbance. Hence, the hysteresis does not depend on weather fire is activated or not in the model CM2Mc-LPJmL. This effect might be due to an imprecise modeling of fire feedbacks in the model or due to the much larger impact of rapidly increasing heat stress on tropical biomass, superimposing a smaller fire impact. If a future climate or land use change leads to a shift of wet tropical rainforest 
to a grassland state, the rapidly burning grass could increase the impact of fire.

\section{Conclusion}

In this study, we present an important step in quantifying the climate-induced hysteresis of tropical forests by investigating changes in biomass, following an atmospheric $\mathrm{CO}_{2}$ perturbation and recovery over the course of 1050 years. We applied the state-of-the-art fireenabled dynamic global vegetation model LPJmL, biophysically coupled to the Earth system model CM2Mc, and simulated the response of potential natural vegetation and fire to changes in climate feedbacks due to elevated atmospheric $\mathrm{CO}_{2}$.

Our results show a delayed recovery of biomass and temperature due to fire-vegetation-climate feedbacks, after an impact and recovery phase of 350 years, respectively. It took another 200 years (post-recovery phase)at constant $\mathrm{CO}_{2}$ level of $284 \mathrm{ppm}$, to reach pre-impact temperature and biomass levels. The system response was spatially heterogeneous, with some regions in the tropics showing an even slower recovery, while other regions exhibited a larger biomass after 200 years of the post-recovery phase. Fire generally had a large impact on vegetation stocks and led to a slightly slower recovery in our experiments.

Biophysical coupling between climate, fire and vegetation, while not considering land use changes, did not lead to large-scale tipping of tropical forests or alternative stable states in vegetation cover. Analyzing the climate-induced hysteresis, only a few smaller regions shifted to a more grassy environment (e.g., Brazilian Cerrado), while other regions increased their tree cover (e.g., eastern Africa). Smaller regions in the tropical forests showed a very strong response to $\mathrm{CO}_{2}$ changes and a very slow recovery after several centuries (e.g., the northern Amazon).

Using an Earth system model that accounts for complex vegetation processes, fire and climate-induced feedbacks, the presented study is an important step in evaluating hysteresis in tropical forests and in quantifying the impact of fire-vegetation-climate interactions.

Acknowledgements This paper was developed within the scope of the IRTG 1740/TRP 2015/50122-0, funded by the DFG/FAPESP (MD, NW and KT). MC acknowledges the support from the projects FAPESP 2015/50122-0 (São Paulo Research Foundation), and CNPq 314016/2009-0 (Brazilian National Council for Scientific and Technological Development). KT and BS acknowledge funding from the BMBF- and Belmont Forum-funded project "CLIMAX: Climate Services Through Knowledge Co-Production: A Euro-South American Initiative For Strengthening Societal Adaptation Response to Extreme Events", Grant No. 01LP1610A. NW is grateful for a scholarship from the Studienstiftung des deutschen Volkes. The authors gratefully acknowledge the European Regional Development Fund (ERDF), the German Federal Ministry of Education and
Research and the Land Brandenburg for supporting this project by providing resources on the high-performance computer system at the Potsdam Institute for Climate Impact Research.

Funding Open Access funding enabled and organized by Projekt DEAL.

\section{Author contribution statement}

MD designed the study with input from KT, BS, WvB and NW. MD conducted the simulations and prepared the figures. MD wrote the initial version of the manuscript with input from all the authors.

Data Availability Statement My manuscript has associated data in a data repository.

\section{Declarations}

Code and data availability The model code of LPJmL4 is publicly available through PIK's gitlab server https:// gitlab.pik-potsdam.de/lpjml/LPJmL. LPJmL5.0 is publicly available under the GNU AGPL version 3 license https:// doi.org/10.5880/pik.2018.011. MOM5 code and example configurations are public available via the project homepage https://mom-ocean.github.io/. Further information about the CM2Mc setup and BLING is available at the Integrated Earth System Dynamics Laboratory https:// earthsystemdynamics.org/models/bling/. Code, input data, and model output of the coupled system are stored in PIK's long-term archive and will be made available to interested parties upon request. It is planned to publish the coupling interface as open source.

Open Access This article is licensed under a Creative Commons Attribution 4.0 International License, which permits use, sharing, adaptation, distribution and reproduction in any medium or format, as long as you give appropriate credit to the original author(s) and the source, provide a link to the Creative Commons licence, and indicate if changes were made. The images or other third party material in this article are included in the article's Creative Commons licence, unless indicated otherwise in a credit line to the material. If material is not included in the article's Creative Commons licence and your intended use is not permitted by statutory regulation or exceeds the permitted use, you will need to obtain permission directly from the copyright holder. To view a copy of this licence, visit http://creativecomm ons.org/licenses/by/4.0/.

\section{References}

1. V. Brovkin, T. Raddatz, C.H. Reick, M. Claussen, V. Gayler, Global biogeophysical interactions between forest and climate. Geophys. Res. Lett. 36(7) (2009). https://doi.org/10.1029/2009GL037543 
2. D.C. Zemp et al., Self-amplified Amazon forest loss due to vegetation-atmosphere feedbacks. Nat. Commun. 8, $1-10(2017)$

3. Importance of Tropical Forests. In Tropical Forest Ecology, + 1-17 ( Springer-Verlag, 2005). https://link. springer.com/chapter/10.1007/3-540-27244-5_1

4. M. Lahsen, M.M.C. Bustamante, E.L. Dalla-Nora, Undervaluing and overexploiting the Brazilian Cerrado at our Peril. Environ.: Sci. Policy Sustain. Dev. 58, 4-15 (2016)

5. J. Barlow, F. França, T.A. Gardner, C.C. Hicks, G.D. Lennox, E. Berenguer, L. Castello, E.P. Economo, J. Ferreira, B. Guénard, C. Gontijo Leal, V. Isaac, A.C. Lees, C.L. Parr, S.K. Wilson, P.J. Young, N.A.J. Graham, The future of hyperdiverse tropical ecosystems. Nature 559(7715), 517-526 (2018). https://doi.org/10. 1038/s41586-018-0301-1

6. M.A. Cochrane, W.F. Laurance, Synergisms among fire, land use, and climate change in the Amazon. Ambio 37, 522-527 (2008)

7. R. Beuchle et al., Land cover changes in the Brazilian Cerrado and Caatinga biomes from 1990 to 2010 based on a systematic remote sensing sampling approach. Appl. Geogr. 58, 116-127 (2015)

8. Y. Malhi, J.T. Roberts, R.A. Betts, T.J. Killeen, W. Li, C.A. Nobre, Climate change, deforestation, and the fate of the Amazon. Science 319(5860), 169-172 (2008). https://doi.org/10.1126/science.1146961

9. E.A. Davidson, A.C. de Araújo, P. Artaxo, J.K. Balch, I.F. Brown, M.M.C Bustamante, M.T. Coe, R.S. DeFries, M. Keller, M. Longo, J.W. Munger, W. Schroeder, B.S. Soares-Filho, C.M. Souza Jr, S.C. Wofsy, The Amazon basin in transition. Nature 481(7381), 321-328 (2012). https://doi.org/10.1038/ nature10717 [Erratum in: Nature 483(7388), 232 (2012)]

10. C.A. Nobre et al., Land-use and climate change risks in the amazon and the need of a novel sustainable development paradigm. Proc. Natl. Acad. Sci. USA 113, 10759 10768 (2016)

11. D.V. Silverio et al., Testing the Amazon Savannization Hypothesis: Fire Effects on Invasion of a Neotropical Forest by Native Cerrado and Exotic Pasture Grasses (Philosophical Transactions of the Royal Society B, Biological Sciences, 2013)

12. L. Gomes, H.S. Miranda, M.M.D.C. Bustamante, How can we advance the knowledge on the behavior and effects of fire in the Cerrado biome? Forest Ecol. Manag. 417, 281-290 (2018)

13. G. Lasslop, V. Brovkin, C.H. Reick, S. Bathiany, S. Kloster, Multiple stable states of tree cover in a global land surface model due to a fire-vegetation feedback. Geophys. Res. Lett. 43, 6324-6331 (2016)

14. P.M. Brando et al., The gathering firestorm in southern Amazonia. Sci. Adv. 6, eaay1632 (2020)

15. S.I. Higgins, S. Scheiter, Atmospheric $\mathrm{CO}_{2}$ forces abrupt vegetation shifts locally, but not globally. Nature 488, 209-212 (2012)

16. M. Hirota, M. Holmgren, E.H. Van Nes, M. Scheffer, Global resilience of tropical forest and savanna to critical transitions. Science 334, 232-235 (2011)
17. D.C. Zemp, C.F. Schleussner, H.M.J. Barbosa, A. Rammig, Deforestation effects on Amazon forest resilience. Geophys. Res. Lett. 44, 6182-6190 (2017)

18. N. Boers, N. Marwan, H.M. Barbosa, J. Kurths, A deforestation-induced tipping point for the South American monsoon system. Sci. Rep. 7, 1-9 (2017)

19. T.M. Lenton, H. Held, E. Kriegler, J.W. Hall, W. Lucht, S. Rahmstorf, H.J. Schellnhuber, Tipping elements in the Earth's climate system. Proc. Natl. Acad. Sci. U S A 105(6), 1786-1793 (2008). https://doi.org/10.1073/ pnas.0705414105

20. M. Baudena, F. DAndrea, A. Provenzale, An idealized model for tree-grass coexistence in savannas: the role of life stage structure and fire disturbances. J. Ecol. 98, 74-80 (2010)

21. A. Staal et al., Hysteresis of tropical forests in the 21st century. Nat. Commun. 11, 4978 (2020)

22. A.C. Staver, S. Archibald, S.A. Levin, The global extent and determinants of savanna and forest as alternative biome states. Science 334, 230-232 (2011)

23. E.D. Galbraith et al., Climate variability and radiocarbon in the CM2Mc earth system model. J. Clim. 24, 4230-4254 (2011)

24. S. Schaphoff et al., LPJmL4 - a dynamic global vegetation model with managed land-Part 1: model description. Geosci. Model Dev. 11, 1343-1375 (2018)

25. W. Von Bloh et al., Implementing the nitrogen cycle into the dynamic global vegetation, hydrology, and crop growth model LPJmL (version 5.0). Geosci. Model De. 11, 2789-2812 (2018)

26. K. Thonicke et al., The influence of vegetation, fire spread and fire behaviour on biomass burning and trace gas emissions: results from a process-based model. Biogeosciences 7, 1991-2011 (2010)

27. M. Drüke et al., Improving the LPJmL4-SPITFIRE vegetation-fire model for South America using satellite data. Geosci. Model Dev. 12, 5029-5054 (2019)

28. M. Drüke, W. von Bloh, S. Petri, B. Sakschewski, S. Schaphoff, M. Forkel, W. Huiskamp, G. Feulner, K. Thonicke, CM2Mc-LPJmL v1.0: Biophysical coupling of a process-based dynamic vegetation model with managed land to a general circulation model. Geosci. Model Dev. (2021). https://doi.org/10.5194/gmd-2020-436 (in press)

29. P.C. Milly, A.B. Shmakin, Global modeling of land water and energy balances. Part I: the land dynamics (LaD) model. J. Hydrometeorol. 3, 283-299 (2002)

30. J.L. Anderson et al., The new GFDL global atmosphere and land model AM2-LM2: evaluation with prescribed SST simulations. J. Clim. 17, 4641-4673 (2004)

31. V. Balaji, The FMS Manual: A developer's guide to the GFDL Flexible Modeling System (2002). http:// www.gfdl.noaa.gov/ vb/FMSManual/FMSManual. html. Accessed 15 Oct 2020

32. S. Schaphoff et al., LPJmL4 - a dynamic global vegetation model with managed land: part 2: model evaluation. Geosci. Model Dev. 11, 1377-1403 (2018)

33. D. Gerten, S. Schaphoff, U. Haberlandt, W. Lucht, S. Sitch, Terrestrial vegetation and water balancehydrological evaluation of a dynamic global vegetation model. J. Hydrol. 286, 249-270 (2004) 
34. A. Bondeau et al., Modelling the role of agriculture for the 20th century global terrestrial carbon balance. Global Change Biol. 13, 679-706 (2007)

35. S. Schaphoff et al., Contribution of permafrost soils to the global carbon budget. Environ. Res. Lett. 8, 14026 (2013)

36. M. Forkel et al., Identifying environmental controls on vegetation greenness phenology through model-data integration. Biogeosciences 11, 7025-7050 (2014)

37. M. Forkel, M. Drüke, M. Thurner, W. Dorigo, S. Schaphoff, K. Thonicke, W. von Bloh, N. Carvalhais, Constraining modelled global vegetation dynamics and carbon turnover using multiple satellite observations. Sci. Rep. 9(1), 18757 (2019). https://doi.org/10.1038/ s41598-019-55187-7

38. J.L. Monteith, Rothamsted repository download. Symposia Soc. Exp. Biol. 205-234 (1965)

39. A.N. Gelfan, J.W. Pomeroy, L.S. Kuchment, Modeling forest cover influences on snow accumulation, sublimation, and melt. J. Hydrometeorol. 5, 785-803 (2004)

40. Chapter 10: Global Climate Projections-AR4 WGI. https://archive.ipcc.ch/publications_and_data/ar4/ wg1/en/ch10.html. Accessed 15 Oct 2020

41. D.A. Clark, D.B. Clark, S.F. Oberbauer, Fieldquantified responses of tropical rainforest aboveground productivity to increasing $\mathrm{CO}_{2}$ and climatic stress, 1997-2009. J. Geophysic. Res.: Biogeosci. 118, 783-794 (2013)
42. G. Lasslop et al., Global ecosystems and fire: Multimodel assessment of fire-induced tree-cover and carbon storage reduction. Glob. Change Biol. 26, 5027-5041 (2020)

43. T. Yokohata et al., Comparison of equilibrium and transient responses to $\mathrm{CO}_{2}$ increase in eight state-of-the-art climate models. Tellus Ser. A: Dyn. Meteorol. Oceanogr. 60, 946-961 (2008)

44. G.B. Bonan, Forests and climate change: forcings, feedbacks, and the climate benefits of forests. Science $\mathbf{3 2 0}$, 1444-1449 (2008)

45. R.M. Callaway, E.H. DeLucia, W.H. Schlesinger, Biomass allocation of montane and desert ponderosa pine: an analog for response to climate change. Ecology 75, 1474-1481 (1994)

46. B. Sakschewski et al., Variable tree rooting strategies improve tropical productivity and evapotranspiration in a dynamic global vegetation model. Biogeosci. Discussions 1-35 (2020)

47. T. Davies-Barnard, et al. Nitrogen cycling in CMIP6 land surface models: progress and limitations. Biogeosciences17, 5129-5148 (2020). https://bg.copernicus. org/articles/17/5129/2020/

48. B.E. Medlyn et al., Temperature response of parameters of a biochemically based model of photosynthesis. II. A review of experimental data. Plant Cell Environ. 25, 1167-1179 (2002) 